\title{
Surface and Tower Meteorological Instrumentation at Atqasuk Handbook
}

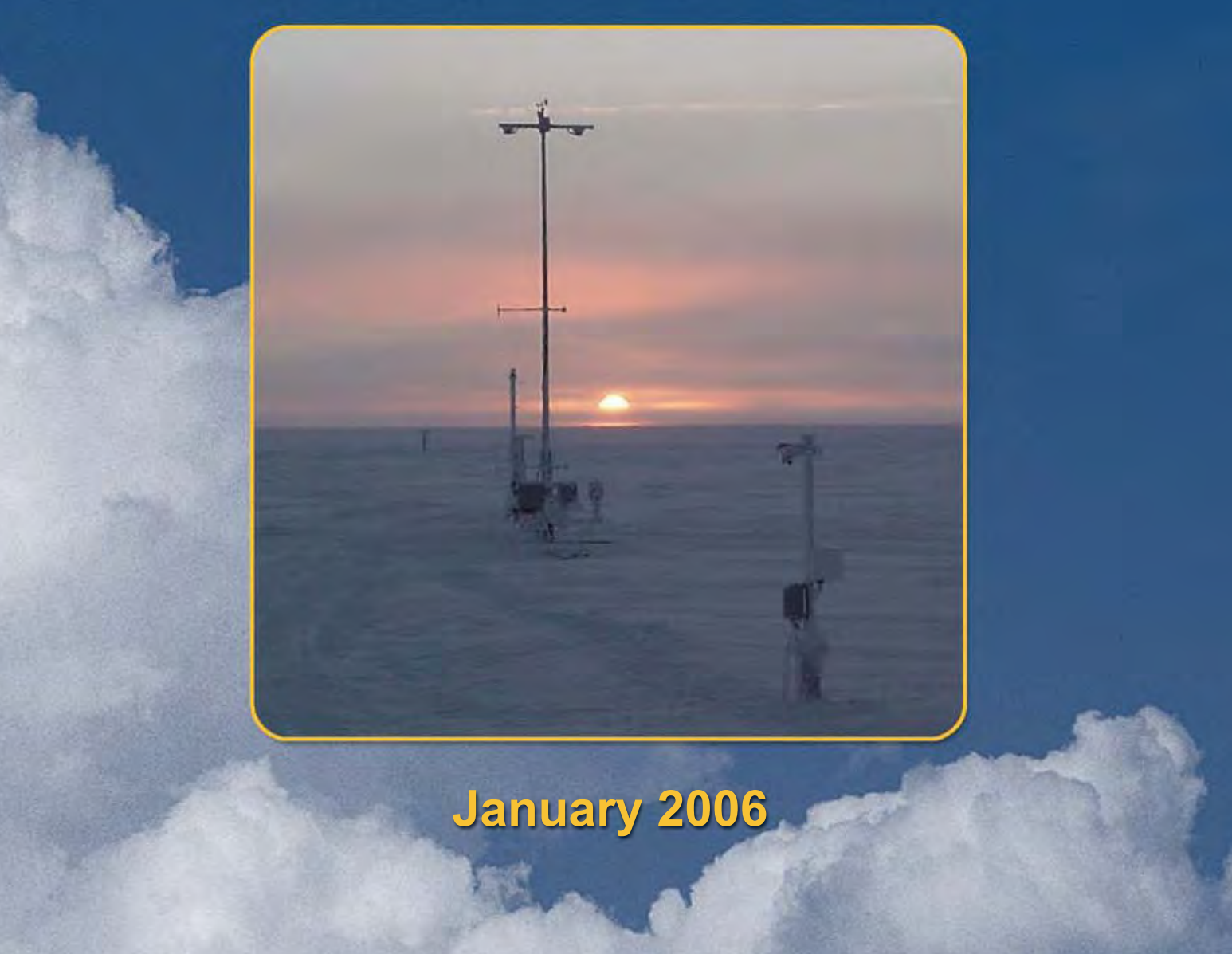




\section{Surface and Tower Meteorological} Instrumentation at Atqasuk (METTWR2H)

\section{Handbook}

January 2006

M.T. Ritsche

Work supported by the U.S. Department of Energy,

Office of Science, Office of Biological and Environmental Research 


\section{Contents}

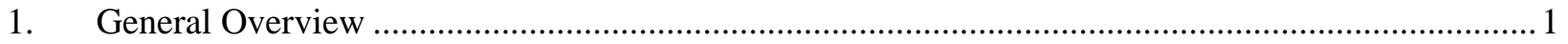

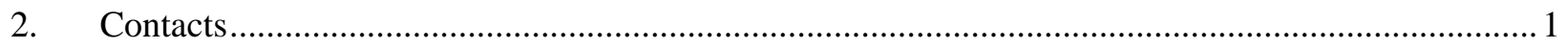

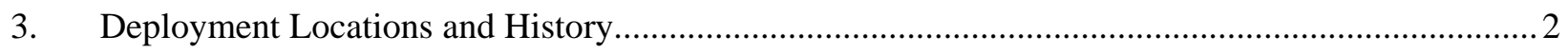

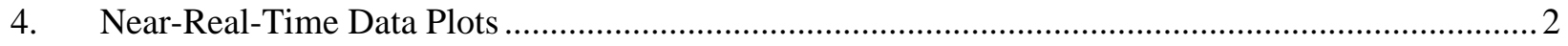

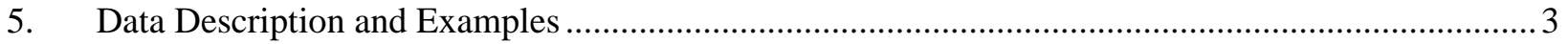

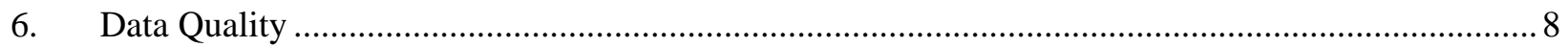

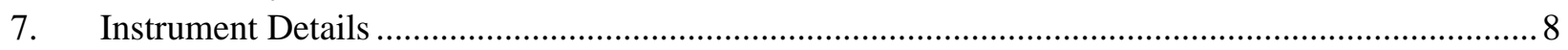

Figures

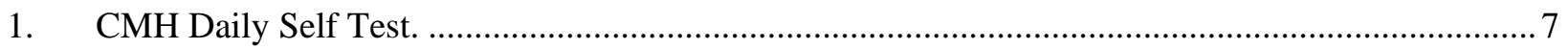

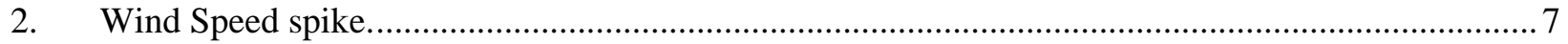

\section{Tables}

1. Deployment Location of the METTWR2H.

2. Primary Variables and Expected Uncertainty........................................................................... 3

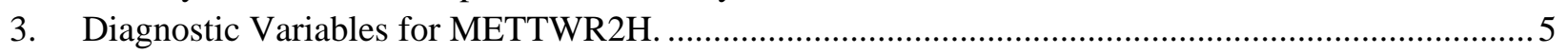

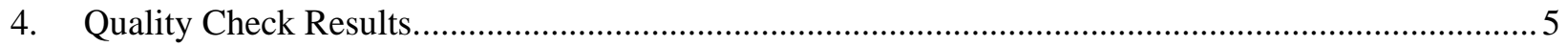

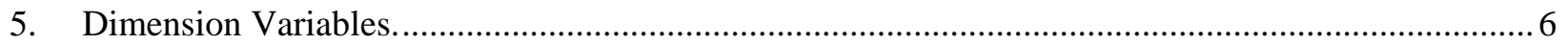




\section{General Overview}

The Atqasuk meteorology station (AMET) uses mainly conventional in situ sensors to measure wind speed, wind direction, air temperature, dew point, and humidity mounted on a 10-m tower. It also obtains barometric pressure, visibility and precipitation data from sensors at or near the base of the tower. In addition, a chilled mirror hygrometer (CMH) is located at $1 \mathrm{~m}$ for comparison purposes. Temperature and relative humidity $(\mathrm{RH})$ probes are mounted at $2 \mathrm{~m}$ and $5 \mathrm{~m}$ on the tower.

\section{Contacts}

\subsection{Mentor}

Michael T. Ritsche, Scientific Associate

Argonne National Laboratory

Bldg. 203

Argonne, IL 60439

Phone: 630-252-1554

Fax: 630-252-5498

Email: mtritsche@anl.gov

\subsection{Instrument Developer}

\section{Wind Speed and Direction, Temperature and Relative Humidity, Barometric Pressure, Present} Weather Sensor

Vaisala

100 Commerce Way

Woburn, MA 01801-1068

Phone: 617-933-4500

Fax: 617-933-8029

Web: http://www.vaisala.com

\section{Aspirated Radiation Shields}

R.M. Young Company

2801 Aero-Park Drive

Traverse City, MI 49686

Phone: 231-946-3980

Fax: 231-946-4772

Web: http://www.youngusa.com

\section{Chilled-Mirror Hygrometer}

Technical Services Laboratory, Inc. 95 Ready Ave.

Fort Walton Beach, FL 32548

Phone: 850-243-3722 


\section{Precipitation}

Scientific Technology, Inc.

205 Perry Parkway, Suite 14

Gaithsburg, MD 20877-2141

Phone: 301-948-6070

Fax: 301-948-4674

\section{Computer}

Dell Optiplex GX270 SFF

Web: http://www.dell.com/

\section{Datalogger and Ethernet Devices}

Campbell Scientific Inc.

815 W. $1800 \mathrm{~N}$.

Logan, UT 84321

Phone: 801-753-2342

Fax: 801-750-9540

Web: http://www.campbellsci.com

\section{Fiber Driver}

Allied Telesyn

19800 North Creek Parkway, Suite 200

Bothell, WA 98011

Phone: 425-487-8880

Fax: 425-489-9191

Toll-free: 1-800-424-6596 (US only)

Web: http://alliedtelesyn.com

\section{Deployment Locations and History}

The original configuration and collection system was installed in July 2000. In October 2003, the configuration and collection system was changed considerably. Information on the data, sensors, and measurement methods before October 2003 can be found at Atqasuk Meteorology Station (AMET).

\begin{tabular}{|c|c|c|c|}
\hline \multicolumn{4}{|c|}{ Table 1. Deployment Location of the METTWR2H. } \\
\hline Location & Date Installed & Date Removed & Status \\
\hline NSA/C2 & $10 / 2003$ & & Operational \\
\hline
\end{tabular}

\section{Near-Real-Time Data Plots}

Near-real-time data plots can be found at the following locations:

- $\quad$ Atqasuk, Alaska Quicklooks

- DQ HandS. 


\section{Data Description and Examples}

See Near-Real-Time Data Plots, Section 4, and Data Quality Health and Status, Section 6.1.

\subsection{Data File Contents}

\subsubsection{Primary Variables and Expected Uncertainty}

Table 2 lists the primary variables of the METTWR2H.

Table 2. Primary Variables and Expected Uncertainty.

\begin{tabular}{|c|c|c|c|c|c|}
\hline Quantity & Variable & Unit & $\begin{array}{c}\text { Measurement } \\
\text { Level }\end{array}$ & $\begin{array}{c}\text { Measurement } \\
\text { Interval }\end{array}$ & Resolution \\
\hline $\begin{array}{l}\text { Arithmetic Mean } \\
\text { Wind Speed }\end{array}$ & WinSpeed_S_WVT & $\mathrm{m} / \mathrm{s}$ & $10 \mathrm{~m}$ & $1 \mathrm{~min}$ & 0.001 \\
\hline $\begin{array}{l}\text { Vector Averaged } \\
\text { Wind Speed }\end{array}$ & WinSpeed_U_WVT & $\mathrm{m} / \mathrm{s}$ & $10 \mathrm{~m}$ & $1 \mathrm{~min}$ & 0.001 \\
\hline $\begin{array}{l}\text { Vector Averaged } \\
\text { Wind Direction }\end{array}$ & WinDir_U_WVT & deg & $10 \mathrm{~m}$ & $1 \mathrm{~min}$ & 0.001 \\
\hline $\begin{array}{l}\text { Standard Deviation of } \\
\text { Vector Averaged } \\
\text { Wind Direction } \\
\end{array}$ & WinDir_SDU_WVT & deg & $10 \mathrm{~m}$ & $1 \mathrm{~min}$ & 0.01 \\
\hline $\begin{array}{l}5 \text { m Average } \\
\text { Temperature }\end{array}$ & T5m_AVG & $\mathrm{C}$ & $5 \mathrm{~m}$ & $1 \mathrm{~min}$ & 0.001 \\
\hline $\begin{array}{l}5 \text { m Average Relative } \\
\text { Humidity } \\
\end{array}$ & RH5m_AVG & $\%$ & $5 \mathrm{~m}$ & $1 \mathrm{~min}$ & 0.01 \\
\hline $\begin{array}{l}5 \mathrm{~m} \text { Average } \\
\text { Calculated Dew Point }\end{array}$ & DP5m_AVG & $\mathrm{C}$ & $5 \mathrm{~m}$ & $1 \mathrm{~min}$ & 0.01 \\
\hline $\begin{array}{l}2 \text { m Average } \\
\text { Temperature }\end{array}$ & T2m_AVG & $\mathrm{C}$ & $2 \mathrm{~m}$ & $1 \mathrm{~min}$ & 0.001 \\
\hline $\begin{array}{l}2 \text { m Average Relative } \\
\text { Humidity }\end{array}$ & RH2m_AVG & $\%$ & $2 \mathrm{~m}$ & $1 \mathrm{~min}$ & 0.01 \\
\hline $\begin{array}{l}2 \text { m Average } \\
\text { Calculated Dew Point }\end{array}$ & DP2m_AVG & $\mathrm{C}$ & $2 \mathrm{~m}$ & $1 \mathrm{~min}$ & 0.01 \\
\hline $\begin{array}{l}5 \text { m Average } \\
\text { Calculated Vapor } \\
\text { Pressure } \\
\end{array}$ & VP5m_AVG & $\mathrm{kPa}$ & $5 \mathrm{~m}$ & $1 \mathrm{~min}$ & 0.001 \\
\hline $\begin{array}{l}2 \text { m Average } \\
\text { Calculated Vapor } \\
\text { Pressure } \\
\end{array}$ & VP2m_AVG & $\mathrm{kPa}$ & $2 \mathrm{~m}$ & $1 \mathrm{~min}$ & 0.001 \\
\hline Atmospheric Pressure & AtmPress & $\mathrm{hPa}$ & $1 \mathrm{~m}$ & $1 \mathrm{~min}$ & 0.1 \\
\hline $\begin{array}{l}1 \text { minute Average } \\
\text { Visibility }\end{array}$ & AvgVis1mi & $\mathrm{m}$ & $2 \mathrm{~m}$ & $1 \mathrm{~min}$ & 1 \\
\hline $\begin{array}{l}10 \text { minute Average } \\
\text { Visibility }\end{array}$ & AvgVis10m & $\mathrm{m}$ & $2 \mathrm{~m}$ & $1 \mathrm{~min}$ & 1 \\
\hline $\begin{array}{l}\text { Instant Present } \\
\text { Weather Code }\end{array}$ & InstPWCod & N/A & $2 \mathrm{~m}$ & $1 \mathrm{~min}$ & N/A \\
\hline
\end{tabular}




\begin{tabular}{|l|c|c|c|c|c|}
\hline \multicolumn{1}{|c|}{ Quantity } & Variable & Unit & $\begin{array}{c}\text { Measurement } \\
\text { Level }\end{array}$ & $\begin{array}{c}\text { Measurement } \\
\text { Interval }\end{array}$ & Resolution \\
\hline $\begin{array}{l}15 \text { minute Present } \\
\text { Weather Code }\end{array}$ & PWcod15mi & N/A & $2 \mathrm{~m}$ & $1 \mathrm{~min}$ & N/A \\
\hline $\begin{array}{l}1 \text { hour Present } \\
\text { Weather Code }\end{array}$ & PWCod1hr & N/A & $2 \mathrm{~m}$ & $1 \mathrm{~min}$ & N/A \\
\hline Precipitation Rate & PCPRate & $\begin{array}{c}\mathrm{mm} / \\
\mathrm{hr}\end{array}$ & $2 \mathrm{~m}$ & $1 \mathrm{~min}$ & 0.01 \\
\hline $\begin{array}{l}\text { Cumulative Water } \\
\text { Sum }\end{array}$ & CumH ${ }_{2} \mathrm{O}$ & $\mathrm{mm}$ & $2 \mathrm{~m}$ & $1 \mathrm{~min}$ & 0.01 \\
\hline $\begin{array}{l}\text { Cumulative Snow } \\
\text { Sum }\end{array}$ & CumSnow & $\mathrm{mm}$ & $2 \mathrm{~m}$ & $1 \mathrm{~min}$ & 0.01 \\
\hline $\begin{array}{l}\text { Chilled Mirror } \\
\text { Temperature }\end{array}$ & CMHTemp & $\mathrm{C}$ & $1 \mathrm{~m}$ & $1 \mathrm{~min}$ & 0.01 \\
\hline $\begin{array}{l}\text { Chilled Mirror Dew } \\
\text { Point }\end{array}$ & CMHDP & $\mathrm{C}$ & $1 \mathrm{~m}$ & $1 \mathrm{~min}$ & 0.01 \\
\hline $\begin{array}{l}\text { Chilled Mirror } \\
\text { Calculated Saturation } \\
\text { Vapor Pressure }\end{array}$ & SatVPCMH & $\mathrm{kPa}$ & $1 \mathrm{~m}$ & $1 \mathrm{~min}$ & 0.01 \\
\hline $\begin{array}{l}\text { Chilled Mirror } \\
\text { Calculated Vapor } \\
\text { Pressure }\end{array}$ & VPCMH & $\mathrm{kPa}$ & $1 \mathrm{~m}$ & $1 \mathrm{~min}$ & 0.01 \\
\hline $\begin{array}{l}\text { Chilled Mirror } \\
\text { Calculated Relative } \\
\text { Humidity }\end{array}$ & CMHRH & $\%$ & $1 \mathrm{~m}$ & $1 \mathrm{~min}$ & 0.1 \\
\hline
\end{tabular}

\subsubsection{Definition of Uncertainty}

We define uncertainty as the range of probable maximum deviation of a measured value from the true value within a $95 \%$ confidence interval. Given a bias (mean) error $B$ and uncorrelated random errors characterized by a variance $\sigma^{2}$, the root-mean-square error (RMSE) is defined as the vector sum of these,

$$
R M S E=\left(B^{2}+\sigma^{2}\right)^{1 / 2}
$$

( $B$ may be generalized to be the sum of the various contributors to the bias and $\sigma^{2}$ the sum of the variances of the contributors to the random errors). To determine the $95 \%$ confidence interval we use the Student's $t$ distribution: $t_{\mathrm{n} ; 0.025} \approx 2$, assuming the RMSE was computed for a reasonably large ensemble. Then the uncertainty is calculated as twice the RMSE.

\subsubsection{Secondary/Underlying Variables}

This section is not applicable to this instrument. 


\subsubsection{Diagnostic Variables}

Table 3 lists the diagnostic variables for METTWR2H.

Table 3. Diagnostic Variables for METTWR2H.

\begin{tabular}{||l|c|c||}
\hline \multicolumn{1}{|c|}{ Quantity } & Variable & Measurement Interval \\
\hline Present Weather Sensor Alarm & PWSAlarm & $1 \mathrm{~min}$ \\
\hline Standard Deviation of 5 m Temperature & T5m_STD & $1 \mathrm{~min}$ \\
\hline Standard Deviation of 5 m Relative Humidity & RH5m_STD & $1 \mathrm{~min}$ \\
\hline Standard Deviation of 5 m Calculated Dew Point & DP5m_STD & $1 \mathrm{~min}$ \\
\hline Standard Deviation of 2 m Temperature & T2m_STD & $1 \mathrm{~min}$ \\
\hline Standard Deviation of 2 m Relative Humidity & RH2m_STD & $1 \mathrm{~min}$ \\
\hline Standard Deviation of 2 m Calculated Dew Point & DP2m_STD & $1 \mathrm{~min}$ \\
\hline $\begin{array}{l}\text { Standard Deviation of 5 m calculated Vapor } \\
\text { Pressure }\end{array}$ & VP5m_STD & $1 \mathrm{~min}$ \\
\hline $\begin{array}{l}\text { Standard Deviation of 2 m Calculated Vapor } \\
\text { Pressure }\end{array}$ & VP2m_STD & $1 \mathrm{~min}$ \\
\hline QLI Average Input Voltage & QLIVolt_AVG & $1 \mathrm{~min}$ \\
\hline QLI Average Reference Temperature & RefTemp_Avg & $1 \mathrm{~min}$ \\
\hline Datalogger Battery Voltage & batt_volt & $1 \mathrm{~min}$ \\
\hline
\end{tabular}

\subsubsection{Data Quality Flags}

Table 4. Quality Check Results.

\begin{tabular}{|l|c|c|c|c|c||}
\hline \multicolumn{1}{|c|}{ Quantity } & Variable & $\begin{array}{c}\text { Measurement } \\
\text { Interval }\end{array}$ & Min & Max & Delta \\
\hline sample time & qc_time & $1 \mathrm{~min}$ & & & \\
\hline Arithmetic Wind Speed & qc_WinSpeed_S_WVT & $1 \mathrm{~min}$ & 0 & 100 & 20 \\
\hline Vector Averaged Wind Speed & qc_WinSpeed_U_WVT & $1 \mathrm{~min}$ & 0 & 100 & 20 \\
\hline Vector Averaged Wind Direction & qc_WinDir_SDU_WVT & $1 \mathrm{~min}$ & 0 & 360 & N/A \\
\hline $5 \mathrm{~m}$ Average Temperature & qc_T5m_AVG & $1 \mathrm{~min}$ & -60 & 30 & 10 \\
\hline $5 \mathrm{~m}$ Average Relative Humidity & qc_RH5m_AVG & $1 \mathrm{~min}$ & -2 & 104 & 30 \\
\hline $5 \mathrm{~m}$ Average Calculated Dew Point & qc_DP5m_AVG & $1 \mathrm{~min}$ & -60 & 30 & 10 \\
\hline $2 \mathrm{~m}$ Average Temperature & qc_T2m_AVG & $1 \mathrm{~min}$ & -60 & 30 & 10 \\
\hline $2 \mathrm{~m}$ Average Relative Humidity & qc_RH2m_AVG & $1 \mathrm{~min}$ & -2 & 104 & 30 \\
\hline $2 \mathrm{~m}$ Average Calculated Dew Point & qc_DP2m_AVG & $1 \mathrm{~min}$ & -60 & 30 & 10 \\
\hline $\begin{array}{l}5 \mathrm{~m} \text { Average Calculated } \\
\text { Vapor Pressure }\end{array}$ & qc_VP5m_AVG & $1 \mathrm{~min}$ & 0.001 & 4.3 & 1 \\
\hline $\begin{array}{l}2 \mathrm{~m} \text { Average Calculated } \\
\text { Vapor Pressure }\end{array}$ & qc_VP2m_AVG & $1 \mathrm{~min}$ & 0.001 & 4.3 & 1 \\
\hline
\end{tabular}


Table 4. (cont'd)

\begin{tabular}{|l|c|c|c|c|c||}
\hline \multicolumn{1}{|c|}{ Quantity } & Variable & $\begin{array}{c}\text { Measurement } \\
\text { Interval }\end{array}$ & Min & Max & Delta \\
\hline Atmospheric Pressure & qc_AtmPress & $1 \mathrm{~min}$ & 800 & 1100 & 10 \\
\hline 1 minute Average Visibility & qc_AvgVis1mi & $1 \mathrm{~min}$ & 0 & 50000 & N/A \\
\hline 10 minute Average Visibility & qc_AvgVis10m & $1 \mathrm{~min}$ & 0 & 50000 & N/A \\
\hline Instant Present Weather Code & qc_InstPWCod & $1 \mathrm{~min}$ & 0 & 99 & N/A \\
\hline 15 minute Present Weather Code & qc_PWcod15mi & $1 \mathrm{~min}$ & 0 & 99 & N/A \\
\hline 1 hour Present Weather Code & qc_PWCod1hr & $1 \mathrm{~min}$ & 0 & 99 & N/A \\
\hline Precipitation Rate & qc_PCPRate & $1 \mathrm{~min}$ & 0 & 999 & 100 \\
\hline Cumulative Water Sum & qc_CumH2O & $1 \mathrm{~min}$ & 0 & 99 & 10 \\
\hline Cumulative Snow Sum & qc_CumSnow & $1 \mathrm{~min}$ & 0 & 999 & 100 \\
\hline Chilled Mirror Temperature & qc_CMHTemp & $1 \mathrm{~min}$ & -60 & 30 & 10 \\
\hline Chilled Mirror Dew Point & qc_CMHDP & $1 \mathrm{~min}$ & -60 & 30 & 10 \\
\hline $\begin{array}{l}\text { Chilled Mirror Calculated } \\
\text { Saturation Vapor Pressure }\end{array}$ & qc_SatVPCMH & $1 \mathrm{~min}$ & 0.001 & 4.3 & 1 \\
\hline $\begin{array}{l}\text { Chilled Mirror Calculated } \\
\text { Vapor Pressure }\end{array}$ & qc_VPCMH & $1 \mathrm{~min}$ & 0.001 & 4.3 & 1 \\
\hline $\begin{array}{l}\text { Chilled Mirror Calculated } \\
\text { Relative Humidity }\end{array}$ & qc_CMHRH & $1 \mathrm{~min}$ & 0 & 101 & 30 \\
\hline
\end{tabular}

\subsubsection{Dimension Variables}

\begin{tabular}{||l|c|c||}
\hline \multicolumn{1}{||c|}{ Table 5. Dimension Variables. } \\
\hline Variable & Measurement Interval & Unit \\
\hline base_time & 1 min & seconds since YYYY-mm-dd XX:XX:XX X:XX \\
\hline time_offset & 1 min & seconds since YYYY-mm-dd XX:XX:XX X:XX \\
\hline time & 1 min & seconds since YYYY-mm-dd XX:XX:XX X:XX \\
\hline lat & 1 min & degrees \\
\hline lon & 1 min & meters above sea level \\
\hline alt & 1 min & \\
\hline
\end{tabular}

\subsection{Annotated Examples}

This section is not applicable to this instrument.

\subsection{User Notes and Known Problems}

Once a day, the $\mathrm{CMH}$ goes through a daily self-test. This is done to remove contaminants from the mirror. It also allows the $\mathrm{CMH}$ to assess the level of contamination remaining on the mirror. When the 
self-test occurs, the mirror is heated to above ambient causing the dew point, $\mathrm{RH}$, vapor pressure and saturation vapor pressure data during the time of self-test and recovery to be incorrect. (see Figure 1 below).
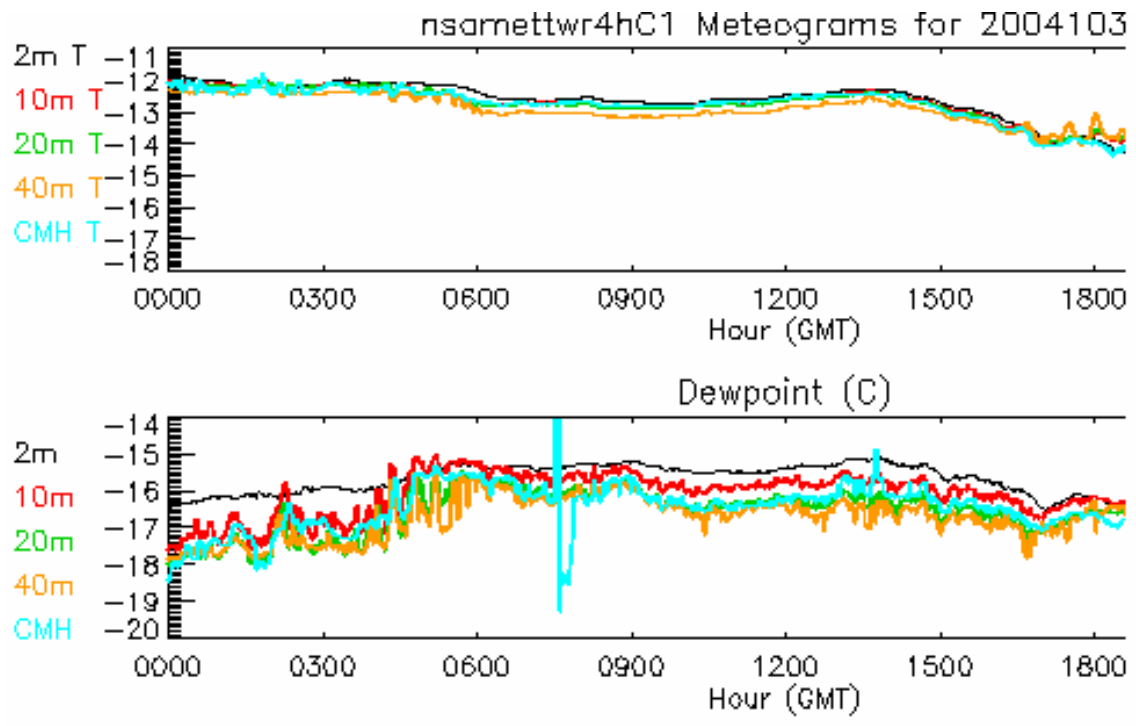

Figure 1. CMH Daily Self Test.

At times, the data from the wind speed and direction sensors is missed when it is sent from the QLI50 Data Collector to the Serial Data Multiplexer. When this occurs, a spike is noticed in the data as the program tries to convert -6999 or -9999 data into vector averages (see Figure 2 below).

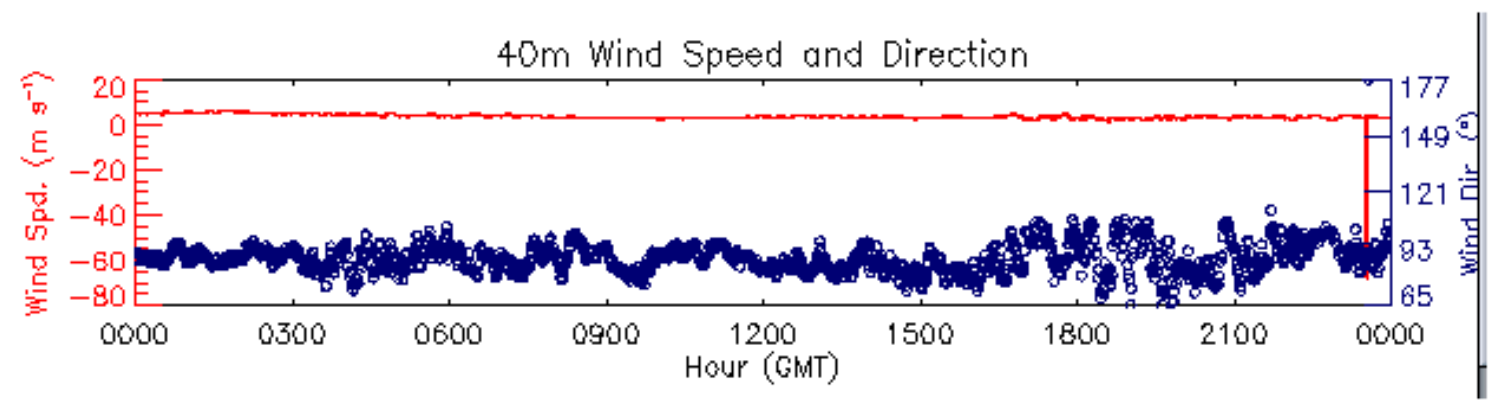

Figure 2. Wind Speed spike.

\subsection{Frequently Asked Questions}

This section is not applicable to this instrument. 


\section{Data Quality}

\subsection{Data Quality Health and Status}

Data Quality Health and Status (DQ HandS) http://dq.arm.gov

NCVweb - for interactive data plotting using http://dq.arm.gov/ncvweb/ncvweb.cgi

\subsection{Data Reviews by Instrument Mentor}

This section is not applicable to this instrument.

\subsection{Data Assessments by Site Scientist/Data Quality Office}

The ARM Data Quality Office uses the Data Quality Assessment (DQA) system to inform the ARM Site Operators, Site Scientists, and Instrument Team members of instrument and data flow problems as well as general data quality observations. The routine assessment reports are performed on the most recently collected ARM data, and used with the Data Quality Problem reports tool to initiate and track the problem resolution process.

http://dq.arm.gov/weekly_reports/weekly_reports.html

\subsection{Value-Added Procedures and Quality Measurement Experiments}

Many of the scientific needs of the ARM Program are met through the analysis and processing of existing data products into "value-added" products (VAPs). Despite extensive instrumentation deployed at the ARM Climate Research Facility (ACRF) sites, there will always be quantities of interest that are either impractical or impossible to measure directly or routinely. Physical models, using ARM instrument data as inputs, are implemented as VAPs and can help fill some of the unmet measurement needs of the program. Conversely, ARM produces some VAPs not to fill unmet measurement needs, but instead to improve the quality of existing measurements. In addition, when more than one measurement is available, ARM also produces "best estimate” VAPs. A special class of VAP called a Quality Measurement Experiment (QME) does not output geophysical parameters of scientific interest. Instead, a QME adds value to the input datastreams by providing for continuous assessment of the quality of the input data based on internal consistency checks, comparisons between independent similar measurements, or comparisons between measurement with modeled results, and so forth. For more information, see the VAPs and QMEs web page.

\section{Instrument Details}

\subsection{Detailed Description}

\subsubsection{List of Components}

Wind Speed Sensor: A Vaisala WAA251 cup anemometer is used to measure the horizontal wind speed. 
Wind Direction Sensor: A Vaisala WAV151 wind vane with heated shaft is used to measure wind direction.

Temperature and Relative Humidity Sensor: A Vaisala HMP45D temperature and RH probe is used to measure air temperature and $\mathrm{RH}$.

Ambient Temperature and Dew Point Temperature: A Technical Services Laboratory Model 1088 hygrothermometer $(\mathrm{CMH})$ is used to measure air temperature and dew point.

Visibility and Precipitation Sensor: A Vaisala FD12P present weather sensor (PWS) is used to measure present weather, visibility and precipitation.

Barometric Pressure Sensor: A Vaisala PTB220 digital barometer is used to measure the station pressure (not corrected to sea level).

\subsubsection{System Configuration and Measurement Methods}

\section{QLI50 Sensor Collector}

A Vaisala QLI50 sensor collector is used to collect data from the wind speed, wind direction, temperature, and RH probes. The QLI50 determines the frequency of the WAA-252 anemometer signals by measuring and averaging the time between pulses. The GRAY code output from the WAV-151 wind vanes is read and converted to angles. The QLI-50 supplys a constant current to the HMP45D platinum resistance detectors and RH circuitry, measures the returned voltages, and converts the voltages to temperatures and RH values. The QLI50 also uses the temperature and RH data to calculate dew point temperatures. The QLI50 also converts the temperature and RH data to dew point values using the following equation:

$$
\begin{aligned}
\operatorname{TDEW} & =\left(\left(\mathrm{c}^{*} \mathrm{~b}\right) /\left(\left(\mathrm{c}^{*}(\mathrm{a} / 2)\right)+\mathrm{b}\right)\right)-273.16 \\
\text { where } \mathrm{a} & =\ln (100 / \mathrm{X} 2), \mathrm{b}=(1.0 * \mathrm{a})-\left(2.1^{*} \mathrm{X} 1\right)+2711.5, \mathrm{c}=\mathrm{X} 1+273.16 \\
\mathrm{X} 1 & =\text { measured air temperature }\left({ }^{\circ} \mathrm{C}\right) \\
\mathrm{X} 2 & =\text { measured RH }(\%)
\end{aligned}
$$

The QLI50 converts the analog data from the sensors to a digital format. The QLI50 sends the data automatically once per second to a Campbell Scientific SDM-SI04 serial data multiplexer. The data is sent via RS-232 to the SDM. The QLI-50 is set for Automatic messaging (AMES 2) at 1-second intervals (REP A 1). A Vaisala WHP25 supplies power to the QLI50.

\section{Power Supplies}

Vaisala WHP25 power supplies are used to power the QLI50 sensor collector, the HMP45D temperature $\mathrm{RH}$ probes, and the heating system for the wind speed and wind direction sensors. The output voltage of the WHP25's is 24VAC. AC to DC converters are used to power the aspirators, which contain the temperature and $\mathrm{RH}$ probes. 


\section{Serial Data Multiplexer}

A Campbell Scientific serial data multiplexer (SDM-SI04) is used to collect data from the serial devices and serial sensors. The barometer, PWS, CMH, and the QLI50 sensor collector send data to the SDM. The SDM converts the serial data it collects to a form the CR23X datalogger can understand using complex filters supplied by the user. The SDM stores complex commands required to request data from the smart serial devices such as the PWS, CMH and barometer. These commands are also user supplied. The SDM has four serial ports that are independently configured to communicate with different sensors.

\section{CR23X Datalogger}

A Campbell Scientific CR23X datalogger is used to acquire and process the data collected by the SDM from the various sensors. Once per minute the datalogger prompts the SDM to request data from the PWS, CMH and barometer. The datalogger also waits for the one-second data from the SDM port connected to the QLI50 at once-per-second intervals. The one-second data from the QLI50 is accumulated in the logger in order to calculate the one-minute data values and statistics. The 1-minute data from the barometer and the PWS is stored while the CMH data are converted from Fahrenheit to Celsius, and RH is calculated from the Celsius temperature and dew point. The following equations are used to convert the temperature and dew point data from the $\mathrm{CMH}$ to $\mathrm{RH}$ values using calculated vapor pressure and saturation vapor pressure:

If temperatures are less than $0^{\circ} \mathrm{C}$ :

Saturation VP $=(6.1359 *(\operatorname{EXP}((22.452 * \mathrm{CMHTemp}) /(272.55+\mathrm{CMHTemp})))) * 0.1$

$\mathrm{VP}=(6.1359 *(\operatorname{EXP}((22.542 * \mathrm{CMHDP}) /(272.55+\mathrm{CMHDP})))) * 0.1$

If temperatures are greater than or equal to $0^{\circ} \mathrm{C}$ :

Saturation VP $=(6.1365 *(\operatorname{EXP}((17.502 * \mathrm{CMHTemp}) /(240.97+\mathrm{CMHTemp})))) * 0.1$

$\mathrm{VP}=(6.1365 *(\operatorname{EXP}((17.502 * \mathrm{CMHDP}) /(240.97+\mathrm{CMHDP})))) * 0.1$

$\mathrm{RH}=100 *(\mathrm{VP} / \mathrm{SatVP})$

Where

CMHTemp $=(5 / 9) *($ measured CMH Temp in F -32.0$)$

$\mathrm{CMHDP}=(5 / 9) *($ measured CMH DP in F -32$)$

Once-per-minute data is sent from the CR23X to the PC upon request. The data is sent via Ethernet through a Campbell Scientific NL-100 network interface, then to an Allied Telesyn media converter through which the data is sent to a partner media converter via fiber optic cable. Once the data reach the end of the fiber, the media converter sends the data through Ethernet cable to a network switch and then onto the PC. The CR23X datalogger includes a 4 Mbyte extended memory option allowing the storage of over 2 million data points in the event of a communication outage. The datalogger has an extended temperature option, which gives it a valid operating temperature range of $-40^{\circ}$ to $+60^{\circ} \mathrm{C}$. The CR23X has been modified so that the Input/Output connectors are removable, allowing for quick connect/disconnect for easy datalogger replacement. 


\section{NL-100 Network Link Interface}

A Campbell Scientific NL-100 network interface is used to communicate with the Campbell Scientific CR23X datalogger. The NL100 uses an Ethernet 10 Base-T communications link between itself and the Allied Telesyn media converter. The NL100 is configured to act as a Serial Server in the TCP/IP network. The unique IP address for the system is stored within the NL100.

\section{AT-MC13 Ethernet Media Converters}

The AT-MC13 media converters are used to convert the data from the CR23X (through the NL100) to fiber optics. Converting to fiber optics and using the media converters allows for a $2 \mathrm{Km}$ maximum operating distance of the network. Two media converters are used; one is located at the base of the towers in the datalogger enclosure, the other is located inside the building at each location. The media converters operate at $10 \mathrm{Mbps}$ and feature half- and full-duplex operation. The media converters also have a MIDI/MDI-X switch. This switch is used to configure the twisted pair port on the media converter as either MIDI or MIDI-X eliminating the need for crossover cables regardless of the type of network device that is connected to the unit. The media converters also have a Fiber Link Test switch that allows testing of the fiber optic connection without requiring the twisted pair port to be connected.

\section{Computer}

The PC used at both Barrow and Atqasuk is a Dell Optiplex GX270 Small Form Factor with a 15” flat panel monitor. The PC contains a Celeron $2.00 \mathrm{GHz}, 400$ Front Side Bus, and 128K Cache processor. It has $512 \mathrm{mb}$ of DDR non-ECC SD-RAM and an Integrated DVMT Video card. The hard drive is an 80 GB EIDE 7200 RPM drive. It also has internal Dell business audio speakers, an integrated Intel Gigabit (10/100/1000) network interface card and an 8x DVD-ROM. The operating system installed on the PC is Microsoft Windows XP Professional using NTFS. The PC was configured to conform to the ARM core PC requirements. The PC is configured to automatically restart and logon after power disruption eliminating the need for human intervention. Campbell Scientifics' LoggerNet software is loaded on the PC and is configured to initialize at start up. LoggerNet is the software application that enables communication and control of the CR23X datalogger. Radmin software is also loaded on the PC allowing remote connection to or control of the local PC. A share-ware program called InternetTime is used to verify and adjust the time of the PC clock once a day. A PERL script called "split_working_cdl.pl” is used to handle the output data file from the LoggerNet software. This script has been installed on both systems in C:\ARM \bin and is scheduled to run once an hour in the LoggerNet task manager. This script creates uniquely named hourly files and places the files in a folder from which the Data Collection System can access, collect and delete them. FTP software allows the Data Collection System to access the PC.

\section{LoggerNet}

LoggerNet software is an application that allows the set up, configuration, and retrieval of data from a network of Campbell Scientific dataloggers. LoggerNet also allows sharing of data over an Ethernet communications network. LoggerNet is written using advanced "client-server" architecture. The server is a software program that runs in the background, handling all of the datalogger communications. The server also takes care of storing the data and providing information to manage the datalogger network. 
Client software programs in LoggerNet are used to create datalogger programs, view and graph data, verify communications on the network, and run other software or tasks.

\subsubsection{Specifications}

\section{Wind Speed Sensor}

The anemometers have heated cups and shafts to prevent ice build up. The anemometers employ a photochopper to produce a $10 \mathrm{~Hz}$ per m/s signal. Vaisala quotes a starting threshold of $<0.5 \mathrm{~m} / \mathrm{s}$, a distance constant of $2.7 \mathrm{~m}$, and a linear output with an accuracy of $+/-0.17 \mathrm{~m} / \mathrm{s}$ from 0.4 to $75 \mathrm{~m} / \mathrm{s}$.

\section{Wind Direction Sensor}

The vanes use an optically detected GRAY code disk with a 5.6 $6^{\circ}$ resolution. Vaisala quotes a starting threshold of $0.4 \mathrm{~m} / \mathrm{s}$, a damping ratio of 0.14 , and overshoot ratio of 0.65 and a delay distance of $0.4 \mathrm{~m}$.

\section{Temperature and Relative Humidity Sensor}

The probes are mounted at two levels ( $2 \mathrm{~m}$ and $5 \mathrm{~m}$ ). Each probe contains a Vaisala HUMICAP sensor and associated electronics along with a 4-wire, platinum resistance temperature detector. The RH output is an analog signal, with 0 to $1 \mathrm{~V}$ corresponding to an $\mathrm{RH}$ of 0 to $100 \%$. Vaisala quotes the accuracy of the RH signal to be $+/-2 \%$ for 0 to $90 \%$ and $+/-3 \%$ for 90 to $100 \%$. The RH sensor has a response time of 15 seconds. The long-term stability is quoted to be better than $1 \% \mathrm{RH}$ per year and a temperature dependence of $+/-0.05 \% \mathrm{RH} /{ }^{\circ} \mathrm{C}$. The measurement range of the RTD is quoted as $-40^{\circ}$ to $+60^{\circ} \mathrm{C}$. Each temperature and RH probe is mounted in a R.M. Young Model 43408-2 aspirated radiation shield. A brushless DC blower provides aspiration.

\section{Ambient Temperature and Dew Point Temperature}

The sensor is mounted near the lowest level temperature and $\mathrm{RH}$ probe near the base of the tower. The Model 1088 measures temperature and dew point over the range of $-80^{\circ}$ to $+130^{\circ} \mathrm{F}$. The accuracy of the temperature measurement is $+/-1^{\circ} \mathrm{RMS}$ in the range of -60 to $+122^{\circ} \mathrm{F}$ and $+/-2^{\circ} \mathrm{F}$ RMS through the remainder of the range. The accuracy of the dew point temperature is $+/-2^{\circ} \mathrm{F}$ RMS from $30^{\circ}$ to $86^{\circ} \mathrm{F}$, $+/-3^{\circ} \mathrm{F}$ RMS from $-10^{\circ}$ to $30^{\circ} \mathrm{F},+/-4^{\circ} \mathrm{F}$ from $-30^{\circ}$ to $-10^{\circ} \mathrm{F}$. No accuracy data for the dew point measurement is available for the rest of the range. The model 1088 consists of two component units, the aspirator and the transmitter. The aspirator contains the dew point assembly and temperature sensor. All of the associated electronics are contained in the transmitter. Data is sent via RS-232 to the collection system when the sensor is polled.

\section{Visibility and Precipitation Sensor}

A Vaisala FD12P PWS is a microprocessor- controlled intelligent device that uses a forward scatter visibility meter, a capacitive rain detector, and a platinum resistance temperature detector to measure visibility and precipitation. The LED light source has a peak-radiated power of $40 \mathrm{~mW}$. The visibility measurement is accurate to $+/-10 \%$ for ranges between 10 and $10,000 \mathrm{~m}$ and $+/-20 \%$ for ranges between 10,000 and $50,000 \mathrm{~m}$. The accuracy of the precipitation intensity measurement is $+/-30 \%$ for the range of 
0.5 to $20 \mathrm{~mm} / \mathrm{hr}$. The LED transmitted light intensity is monitored and used to compensate for temperature and aging effects. Data is sent via RS-232 to the collection system when the sensor is polled.

\section{Barometric Pressure Sensor}

The barometer uses a Vaisala BAROCAP silicon capacitive absolute pressure sensor. Vaisala quotes the operating temperature as $-40^{\circ}$ to $+60^{\circ} \mathrm{C}$ and the pressure measurement range as 500 to $1100 \mathrm{hPa}$. The total accuracy over the measurement range is given to be $+/-0.15 \mathrm{hPa}$. Data is sent via RS-232 to the collection system when the sensor is polled.

\subsection{Theory of Operation}

Surface meteorological data is collected at the ACRF North Slope of Alaska (NSA) locale at two sites: Barrow, Alaska, and Atqasuk, Alaska. At the site in Atqasuk data is collected at the base of a 10-m tip tower and at various heights on the tower. Temperature and $\mathrm{RH}$ are collected at $2 \mathrm{~m}$ and $5 \mathrm{~m}$ while wind speed and direction are collected at $10 \mathrm{~m}$.

The data are collected at the base of the tower using a Campbell Scientific CR23X datalogger. The datalogger is polled once a minute by Campbell Scientific LoggerNet software. The LoggerNet software runs on a Dell Optiplex GX270 small form-factor computer using Microsoft XP Professional as the operating system. The computer system is configured such that if power is interrupted it will automatically restart eliminating the need for human intervention. The LoggerNet software has been added to the start menu so that it will automatically begin to collect data from the dataloggers as soon as the system has re-booted.

The data from the datalogger are stored in a single location and the data are appended to an everincreasing file. A PERL script has been written to search the data file once an hour to capture a single hours worth of data $(00-59)$ and copy the data to another file location with a unique time and date name. The file is then deleted preventing a large, single file that continues to grow. The hourly files created by the PERL script are collected once an hour using FTP and the collected file is then deleted from the local PC.

Remote Administrator (RAdmin) software has been loaded to the computer so that remote access is available for loading new programs, troubleshooting, etc. Access is limited to the site observers, mentors, and selected operations personnel.

Temperature, RH (from two levels), wind speed and direction are collected once per second. The onesecond analog data is collected by a Vaisala QLI data collector and is sent via serial cables to the CR23X datalogger once per second where it is accumulated to create 1-minute averages and other calculated variables. Data is collected from the other sensors near the base of the tower once each minute. The PWS, CMH, and barometric data are collected once per minute at each location. Data from each of the sensors at the base of the tower transmit their data via serial cable.

The serial data from all sensors is sent to, or requested by, a Campbell Scientific serial data multiplexer (SDM-SIO4). An SDM-SIO4 has four ports and a unique address so that multiple SDMs can be 
connected to each logger. The SDM contains programming for the communication protocols (baud rate, data bits, etc) and filters so data can be converted to a form the CR23X can accept.

The data collected by the logger is requested by the LoggerNet system once per minute. The data is sent by the CR23X datalogger to the computer via a network connection. A Campbell Scientific NL-100 network interface is used to send the data via an RS-232 serial connection from the logger to the computer. The NL-100 allows each datalogger to have a unique network address. The data is passed from the NL-100 to an Allied Telesyn AT-MC13 media converter via a Cat-5 Ethernet cable. The media converter sends the data via a fiber optic cable to another media converter inside the building where it is sent through a network switch and onto the computer.

The data that is collected from the datalogger can be viewed locally at each sites computer. A program contained in the LoggerNet software package called Real Time Monitor and Control (RTMC) is used to plot graphs of the data and view data values, allowing observers to verify proper operation of the system and sensors. The raw one-second data can also be viewed to assist in troubleshooting.

\subsection{Calibration}

\subsubsection{Theory}

The AMET is not calibrated as a system. The sensors along with the Sensor Collectors and the instruments are calibrated separately. The system was installed using components that had a current calibration.

\subsubsection{Procedures}

\section{Daily Checks}

The data from the tower are checked each day during daily rounds. Temperature and RH data from the $2 \mathrm{~m}$ level and the $\mathrm{CMH}$ are compared to determine if the data appear reasonable. The T/RH data between the difference levels is compared also to determine if the data appear to be reasonable. Any discrepancies are noted on the daily rounds forms. The wind speed and direction is compared and checked against local conditions. The barometric and present weather data is checked to determine if what is being reported also appears reasonable. For example, if the PWS is reporting $100 \mathrm{~m}$ visibility and heavy snow when the sky is clear and sunny, this indicates a problem with the PWS and is noted. The PWS also has an alarm value. If everything is working properly the alarm reading is 0 , if there is a problem the alarm reading will be 1 . Data from the barometer should be between 800 and $1100 \mathrm{hPa}$. If the barometric data is outside of these values then it is noted on the daily forms. A view screen has been built which displays 24 hours of data graphed along with text values for the current readings. The graphs allow checks of the data to be made to determine if problems have occurred during the most recent 24 hours. Long gaps in data, long periods of or many data spikes, and flat line data (no change in values over extended periods) will be apparent and are noted on the daily forms. 


\section{Monthly Checks}

Once a month, the auto balance dial reading is taken for the CMH. The auto balance reading is an indication of the contamination on the surface of the mirror. This value is recorded once a month on the daily forms. When the reading reaches or exceeds 500 , the mirror is cleaned and the entire sensor is recalibrated.

\section{Six-Month Checks}

\section{Present Weather Sensor}

The lenses of the PWS are cleaned along with the capacitive rain detector every six months.

\section{Chilled Mirror Hygrometer}

The CMH is cleaned and recalibrated every six months to ensure proper functioning and that reasonable data is returned from the sensor.

\section{Annual Checks}

\section{Cup Anemometers and Wind Direction Vanes}

The bearings in these sensors are checked once a year. The cups and vane are inspected for any signs of damage. If any irregularity is observed, the respective anemometer or wind direction sensor is replaced.

\section{HMP45D Temperature and Relative Humidity Probes}

The filters on the probes are checked once a year and replaced if dirty.

\section{PTB201 or PTB220 Digital Barometer}

The reading of the digital barometer is compared with the reference digital barometer.

\section{FD12P Present Weather Sensor}

The visibility calibration is checked once a year using the FDA12 calibration kit.

\section{Two-Year Checks and Replacement}

\section{Wind Speed and Direction Sensors}

The calibration of the current cup anemometers and the frequency measuring portion of the QLI50 Sensor Collectors are checked by using the R.M. Young Model 18810 Anemometer Drive to spin the anemometer shafts for at least one minute at the different rpms. The calibration of the current wind vanes and decoding portion of the QLI50 Sensor Collector is also checked. The sensors are then replaced and the newly installed sensors are checked to ensure the values fall within manufacturers specifications.

\section{Temperature and Relative Humidity Sensors}

The calibration of the current temperature and $\mathrm{RH}$ probe is checked by comparing it to the reference probe. The probe is then replaced with one that has a current calibration. The calibration of the newly replaced probe is also checked before returning to service. 


\subsubsection{History}

On September 23, 2002, both T/RH probes and the wind speed and direction sensors were replaced and a field calibration on the sensors was accomplished. All were within tolerances.

Serial Numbers:

Wind Speed Sensor: U21107 Wind Direction Sensor: W07444

2 m T/RH: W4940013 5 m T/RH: U4940014

PWS calibrated.

On October 18, 2004, both T/RH probes and the wind speed and direction sensors were replaced and a field calibration on the sensors was accomplished. All were within tolerances.

Serial Numbers:

Wind Speed Sensor: U21109 Wind Direction Sensor: U48507

2 m T/RH: W2110047 tm T/RH: W2110045

PWS was calibrated and the CMH cleaned and calibrated.

On January 18, 2005, the Wind Direction Sensor was replaced.

Serial Number: V36301

On September 5, 2005, the $2 \mathrm{~m} \mathrm{T/RH}$ probe was replaced.

Serial Number: W2110041

On October 15, 2005, both T/RH probes and the wind speed and direction sensors were replaced and a filed calibration on the sensors was accomplished. All were within tolerances.

Serial Numbers:

Wind Speed Sensor: V37502 Wind Direction Sensor: W23229

$2 \mathrm{~m}$ T/RH: A3930010 5 m T/RH: A3930011

PWS was calibrated and the CMH cleaned and calibrated.

\subsection{Operation and Maintenance}

\subsubsection{User Manual}

This section is not applicable to this instrument.

\subsubsection{Routine and Corrective Maintenance Documentation}

This section is not applicable to this instrument.

\subsubsection{Software Documentation}

See http://science.arm.gov/tool/dod/showdod.php?Inst=mettwr2h.

\subsubsection{Additional Documentation}

This section is not applicable to this instrument. 


\subsection{Glossary}

See the ARM Glossary.

\subsection{Acronyms}

See the ARM Acronyms and Abbreviations.

\subsection{Citable References}

None. 